\title{
Did States With More Social Capital Pre-pandemic Offer Mental Health Protection During the COVID-19 Pandemic? A Cross-sectional View
}

Kim Nichols Dauner ( $\sim$ kdauner@d.umn.edu )

University of Minnesota Duluth

Neil A. Wilmot

University of Minnesota Duluth

\section{Research Article}

Keywords: Mental health, social capital, COVID-19

Posted Date: September 28th, 2021

DOI: https://doi.org/10.21203/rs.3.rs-926013/v1

License: (c) (1) This work is licensed under a Creative Commons Attribution 4.0 International License.

Read Full License 


\section{Abstract}

Background: Mental health has declined during the COVID-19 pandemic, and social capital, as a determinant of health, may serve to buffer those declines.

Methods: Building from this, we assessed whether pre-pandemic social capital, which included indicators of social trust, civic participation, and the presence of mask mandates affected pandemic mental health, measured as the percent of the population experiencing symptoms of depression and anxiety at the state level.

Results: Generalized social trust and state mask mandates were significantly associated with lower levels of depression and anxiety. Conversely, states with greater civic engagement prior to the pandemic experienced more anxiety and depression.

Conclusions: Findings suggest that existing social capital, particularly social trust, may protect against anxiety and depression and contribute to community resilience during times of adversity. States should invest in policies and programs that increase social trust.

\section{Background}

Mental health has declined over the course of the COVID-19 pandemic (1). Social capital, which has been defined as the features of social organization that facilitate cooperation for mutual benefit, and is often measured through the constructs of social trust and civic participation, has been known to positively affect mental health at both individual(2) and state levels (3). Additionally, there is increasing recognition that social capital is a key factor in mitigating the impacts of adverse events (4). When it comes to the COVID-19 pandemic, social capital appears to play a role in reducing risk of infection(5) and government response (6). Conversely, social vulnerability has been associated with increased COVID-19 cases and deaths (7). On their face, these findings illustrate how social environments impact mental health, including during COVID-19. However, it is not known how a state's pre-pandemic social capital impacted mental health during the pandemic. To provide the necessary evidence we capitalize on timely data from the Centers for Disease Control's Pulse Survey on population mental health during the pandemic, and interstate variability in mental health outcomes and social capital indicators and assess whether statelevel pre-pandemic social capital affects pandemic mental health.

\section{Methods}

The study was cross-sectional, at the state level. We used publicly available data from all 50 U.S. states, along with the District of Columbia, compiled from several sources. The dependent variable was the percent of persons in a state reporting symptoms of anxiety or depression on the Centers for Disease Control's Pulse Survey during the period ending February 15, 2021 (8). Chosen due to its contemporary nature, there does not appear to be anything statistically special or unique about this period. The average 
state reporting level is within 0.5 standard deviation units from the average value of the 27 periods beginning April 23, 2020.

Independent variables on state-level social capital data precede the pandemic and were obtained from the United States Congress Joint Economic Committee's The Geography of Social Capital in America project (9). Social trust was measured as the percentage of the population that 'trust all or most of their neighbors'. This is a primary measure frequently used to compare social trust internationally (10). Civic participation was an index aggregating eight individual measures (number of membership organizations per 1,000; religious and non-religious non-profits per 1,000; and percent of population who in the last year had: attended a meeting to discuss politics, participated in a demonstration, volunteered for a group, attended a public meeting, worked with neighbors to improve something, and served on a committee or group officer). This index is standardized so its mean is zero and the standard deviation equals one. A third indicator of social capital was whether the state had a mask mandate (coded as no mandate, situational, or sweeping) in effect as of February 26, 2021 (11). We chose this indicator recognizing the relationship between social trust and government performance when large-scale collective action is needed, as was the case during the pandemic (12).

We also controlled for state-level population characteristics that are known to impact mental health and obtained these data from the Census Bureau (13). Characteristics included percentage of the population below the poverty level, percentage of the state's population over age 65 , and percentage of the state's population that is Black or African American. State unemployment rates were obtained from the Federal Reserve Economic Database and used to calculate the difference between the unemployment rate in February 2021 compared to January 2020 (14). Finally, we controlled for state level pre-pandemic mental health by using age-adjusted percentage of adults reporting 14 or more days of poor mental health per month in the state in 2018 (15). Linear regression was used to analyze the effect of the social capital variables on reported anxiety and depression.

\section{Results}

State level percentages of persons reporting symptoms of anxiety and depression ranged from a low of $29.2 \%$ (Wyoming), to a high of $45.1 \%$ (Oregon), with a median value of $38.7 \%$ (Fig. 1). Scores for the civic participation index ranged from a high of 3.97 in the District of Columbia to a low of -1.38 in Florida; 20 states had civic participation levels below the mean, with the remaining 30 states and the District of Columbia performing above the mean. (Fig. 2). Levels of perceived social trust varied considerably across the U.S. and ranged from a high of $76.8 \%$ reporting that they 'trust all or most of their neighbors' in Utah, to a low of $41.2 \%$ in Nevada (Fig. 3). Figure 4 depicts state mask mandates as of February 26, 2021. Eleven states had no mask mandate whatsoever, six had a situational mask mandate, and the remaining 33 states and the District of Columbia had a universal and mandatory mask mandate.

Regression results are presented in Table 1. At the state level, the social trust is negative and significant, indicating that states where citizens report higher levels of trust among neighbors, had fewer individuals 
reporting symptoms of anxiety or depression in February 2021. Likewise, the effect of a state face mask policy is negative and significant, meaning that such policies are predictive of lower levels of anxiety and depression. In contrast, the coefficient on the civic participation index is positive and significant at $10 \%$, which suggests that communities with greater civic engagement prior to the pandemic experienced more anxiety and depression. Additionally, there is a positive and significant coefficient on the percent of the population over the age of 65 , with larger percentages predicting higher levels of anxiety and depression.

Table 1

Regression results for state level symptoms of anxiety and depression in U.S. adults, U.S. Household Pulse Survey

\begin{tabular}{|c|c|c|c|c|}
\hline Variable & Mean & Std. Dev. & Coefficient & $p$ - value \\
\hline Mental health & 38.4 & 3.42 & - & - \\
\hline Social trust & 59.8 & 8.64 & $-0.2432^{\star \star \star}$ & $(0.005)$ \\
\hline Civic participation & 0.00 & 1.0 & $0.8974^{\star}$ & $(0.064)$ \\
\hline Mask mandate & 1.4 & 0.83 & $-1.271 \star \star$ & $(0.050)$ \\
\hline$\Delta$ unemployment & 2.0 & 1.51 & 0.6121 & $(0.153)$ \\
\hline Poverty & 12.2 & 2.68 & 0.1238 & $(0.619)$ \\
\hline \% Population over 65 & 16.9 & 2.02 & $0.3989 *$ & $(0.091)$ \\
\hline$\%$ Population Black & 26.0 & 14.87 & 0.0383 & $(0.370)$ \\
\hline Covid cases per capita & 9322.4 & 2438.56 & -0.0003 & $(0.198)$ \\
\hline Pre-pandemic mental health & 13.3 & 2.21 & -0.1150 & $(0.666)$ \\
\hline Constant & - & - & $47.1619 * \star \star$ & $(0.000)$ \\
\hline R-square & - & - & 0.4113 & - \\
\hline
\end{tabular}

\section{Discussion}

The findings provide a first look into states' social capital and how that social capital may confer mental health protection during the COVID-19 pandemic. We found that states with higher levels of social trust pre-pandemic tended to also have fewer persons experiencing symptoms of anxiety and depression, suggesting that their neighborly relations and sense of community may mitigate these symptoms. As expected, state mask mandates were associated with lower percentages of persons reporting anxiety and depression and could indicate that citizens feel less anxiety knowing the state is actively trying to prevent virus spread. States with higher levels of pre-pandemic civic participation reported greater symptoms of anxiety and depression during the pandemic, although this finding was only significant at the $10 \%$ level. While somewhat counterintuitive, it could be a reflection of how the pandemic has limited social 
interaction, leading to elevated occurrences of anxiety and depression among the residents in those states and fits with other research in this area (6). Our findings compliment those of Bodes and Peleg who find that increased social trust was associated with greater compliance with self-quarantine regulations in Israel (16). We also found that higher percentages of persons over the age of 65 was related to increased anxiety and depression, which may reflect the increased risk of hospitalization and death due to COVID-19 in this age group (17). Finally, these aspects of social capital are significant, even while controlling for pre-pandemic mental health.

Overall, there was wide variation in social capital across states. The range between the least trusting states and the most is over $35 \%$, with no apparent regional clustering of states. Similarly, as shown in Fig. 2, civic participation is variable, but appears to be lower in the South and Southwest. The wide variation indicates that social trust is changeable, though more research is needed into the specific policies and social supports that results in higher social trust.

A limitation of the research is that the data is cross sectional and cannot establish causality, albeit the independent variables are captured from an earlier time point compared to the dependent variable. We only measured bonding aspects of social capital and assumed that the social capital variables were relatively static during the pandemic; however, some research has found declining trust over the course of the pandemic (16). Future research should continue to explore how social capital changed over the course of the pandemic and explore the impact of bridging and linking social capital on mental health and community resiliency. Similarly, this research cannot rule out the presence of important but unmeasured variables.

Our findings support the importance of state level social capital on mitigating the adverse mental health effects associated with the COVID-19 pandemic. Donnelly and Farina, also using Pulse data, found the provision of economic support - Medicaid, unemployment insurance, and suspended utility shut offs -

provided a buttress against the impact of household income shocks on mental health (18). Similarly, our research supports the notion that social policies, many of which are enacted and enforced at state level, can support mental health. In addition to mask policies suggestions to increase social capital include increasing institutional effectiveness, accountability and transparency, and responding to citizen concerns (19).

\section{Conclusions}

Findings suggest that existing social capital, particularly social trust, may protect against anxiety and depression and contribute to community resilience during times of adversity. States should invest in policies and programs that increase social trust.

\section{Declarations}

Ethics approval and consent to participate

Page 5/9 
Not applicable

\section{Consent for publication}

Not applicable

\section{Availability of data and materials}

All primary data is publicly available and referenced in the manuscript. The data secondarily analyzed during the current study are available from the corresponding author on reasonable request.

\section{Competing interests}

The authors declared no potential conflicts of interest with respect to the research, authorship, and/or publication of this article.

\section{Funding}

Not applicable

\section{Authors' contributions}

KND designed the study. Both authors identified data sources and interpreted the analysis. NAW analyzed data. KND wrote the initial draft of the manuscript. Both authors edited subsequent drafts of the paper and have read and approve the final version.

\section{Acknowledgements}

We thank Daniel G. Dauner, MSPH, PharmD for creating the maps herein.

\section{References}

1. Swaziek Z, Wozniak A. Disparities Old and New in US Mental Health during the COVID-19 Pandemic. Fisc Stud. 2020 Sep;41(3):709-32.

2. Ehsan AM, Silva MJD. Social capital and common mental disorder: a systematic review. J Epidemiol Community Health. 2015 Oct 1;69(10):1021-8.

3. Kim D, Kawachi I. U.S. State-Level Social Capital and Health-Related Quality of Life: Multilevel Evidence of Main, Mediating, and Modifying Effects. Annals of Epidemiology. 2007 Apr 1;17(4):25869.

4. Aldrich DP, Meyer MA. Social Capital and Community Resilience. American Behavioral Scientist. 2015 Feb;59(2):254-69.

5. Makridis CA, Wu C. How social capital helps communities weather the COVID-19 pandemic. PLOS ONE. 2021 Jan 29;16(1):e0245135. 
6. Ding W, Levine R, Lin C, Xie W. Social Distancing and Social Capital: Why U.S. Counties Respond Differently to COVID-19 [Internet]. National Bureau of Economic Research; 2020 Jun [cited 2021 May 4]. Report No.: w27393. Available from: https://www.nber.org/papers/w27393

7. Islam N, Lacey B, Shabnam S, Erzurumluoglu AM, Dambha-Miller H, Chowell G, Kawachi I, Marmot M. Social inequality and the syndemic of chronic disease and COVID-19: county-level analysis in the USA. J Epidemiol Community Health. 2021 Jun 1;75(6):496-500.

8. Mental Health Care - Household Pulse Survey - COVID-19. Centers for Disease Control and Prevention, Atlanta, GA. 2021. https://www.cdc.gov/nchs/covid19/pulse/mental-health-care.htm. Accessed 1 Apr 2021.

9. The Geography of Social Capital in America. United States Congress Joint Economic Committee, Washington, DC. 2018. https://www.jec.senate.gov/public/index.cfm/republicans/2018/4/thegeography-of-social-capital-in-america. Accessed 1 Apr 2021.

10. OECD. OECD Guidelines on Measuring Trust [Internet]. OECD; 2017 [cited 2021 Sep 18]. Available from: https://www.oecd-ilibrary.org/governance/oecd-guidelines-on-measuringtrust_9789264278219-en

11. Coronavirus Restrictions and Mask Mandates for All 50 States. The New York Times, New York, NY. 2021. https://www.nytimes.com/interactive/2020/us/states-reopen-map-coronavirus.html. Accessed 26 Feb 2021.

12. Knack SF. Social Capital and the Quality of Government: Evidence from the United States. World Bank Publications; 2000. 38 p.

13. American Community Survey (ACS). The United States Census Bureau, United States. 2019. https://www.census.gov/programs-surveys/acs. Accessed 1 Apr 2021.

14. Federal Reserve Economic Data. Federal Reserve Bank, St. Louis, MO. 2021. https://fred.stlouisfed.org/. Accessed 1 Apr 2021.

15. County Health Rankings and Roadmaps. University of Wisconsin Population Health Institute, Madison, WI. 2021. https://www.countyhealthrankings.org/. Accessed 11 Sept 2021.

16. Bodas M, Peleg K. Pandemic Fatigue: The Effects Of The COVID-19 Crisis On Public Trust And Compliance With Regulations In Israel: The study examines the effects of the COVID-19 crisis on public trust and compliance with regulations in Israel. Health Affairs. 2021 Aug 1;40(8):1225-33.

17. Yanez ND, Weiss NS, Romand J-A, Treggiari MM. COVID-19 mortality risk for older men and women. BMC Public Health. 2020 Nov 19;20(1):1742.

18. Donnelly R, Farina MP. How do state policies shape experiences of household income shocks and mental health during the COVID-19 pandemic? Social Science \& Medicine. 2021 Jan;269:113557.

19. Stanford Social Innovation Review: Six Ways to Repair Declining Social Trust. https://ssir.org/articles/entry/six_ways_to_repair_declining_social_trust (2019). Accessed 30 Apr 2021.

\section{Figures}


Figure 1. Percent of persons reporting symptoms of anxiety or depression by State, 2020-2021

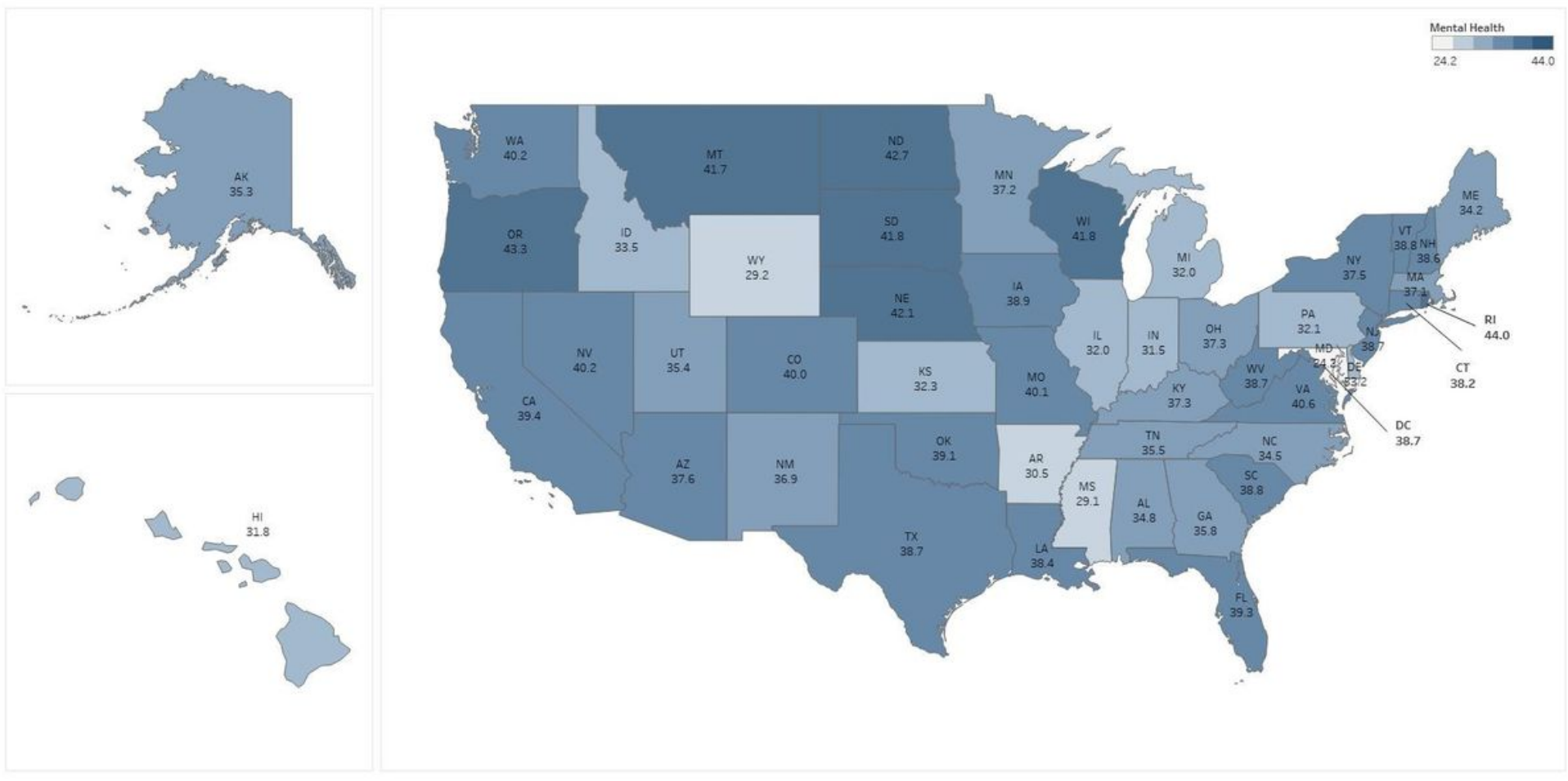

\section{Figure 1}

See image above for figure legend.

Figure 2. Civic participation by state, 2020-2021

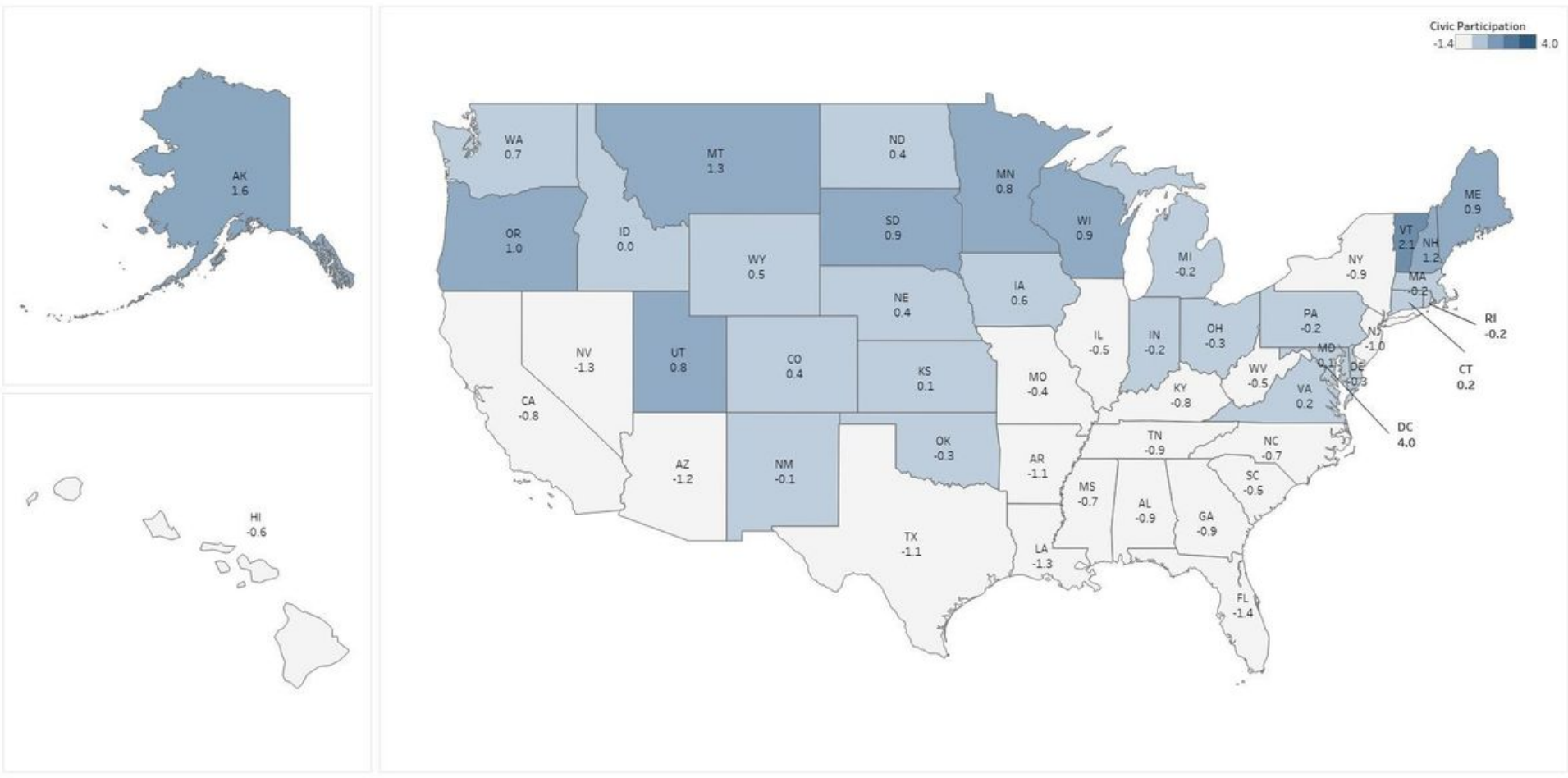

Figure 2

See image above for figure legend. 


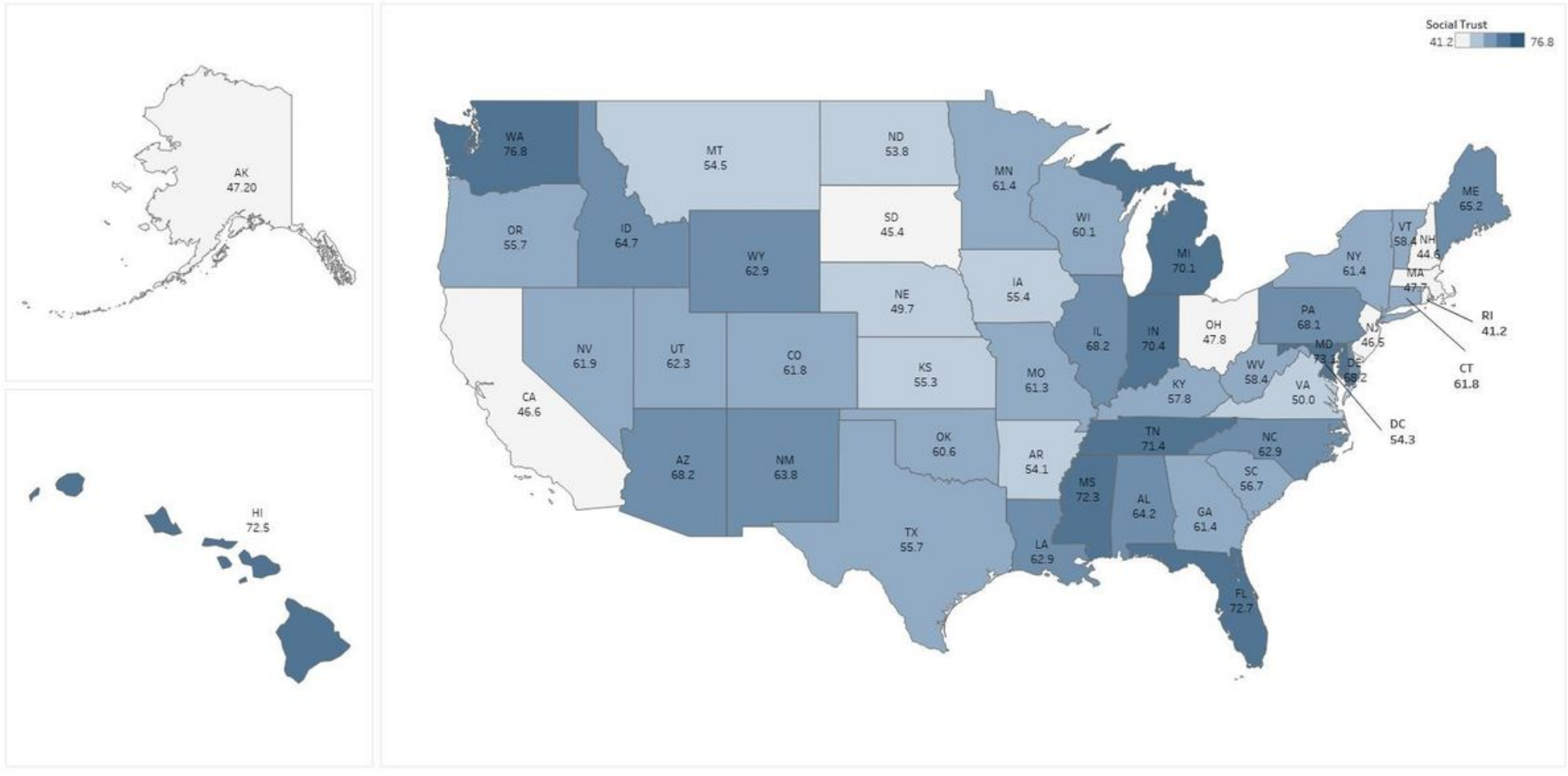

\section{Figure 3}

See image above for figure legend.

Figure 4. Mask mandates by state, 2020-2021

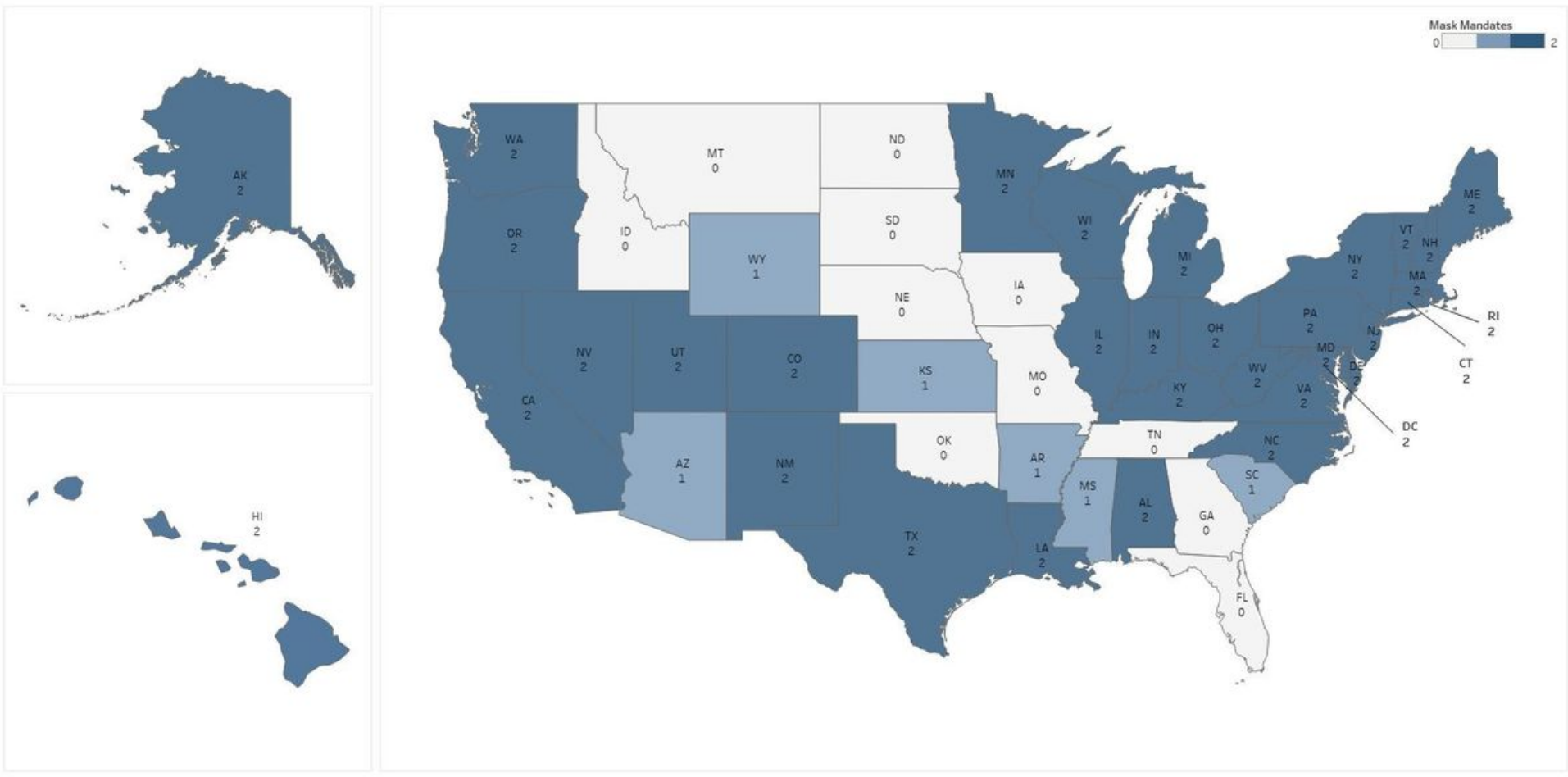

\section{Figure 4}

See image above for figure legend. 